\title{
Study of the Impact of Innovation Capacity Factors on the Activation of Company's Innovation Activity
}

\section{Mladen Velev*, Siya Veleva"*}

\section{Abstract}

The more topical the issues and the importance of innovations get, the higher the interest in theoretical clarification and empirical study of various aspects of the innovation capacity of enterprises. The number of scientific publications in these areas of research is growing. However, a number of important issues require additional research, which justifies the need to conduct new studies in certain areas. Such an area of research is the study of the impact of the factors of innovation capacity of enterprises on their innovative activity.

In view of the above, the aim of this paper is to present the findings of an empirical study of the impact of the factors of innovation capacity on the innovative activity of some industrial enterprises in Bulgaria. The authors hope to initiate a discussion on these issues and other similar questions related to the topic, the results of which will aid enterprises in taking managerial decisions on both streamlining innovative efforts and investment, and developing strategies for further growth.

Keywords: innovation, innovation capacity, determinants, factors, study, results.

JEL: 030, 031.

\section{Introduction}

Company innovation involves the introduction of novelties which ensure a higher degree of satisfaction of costumers' needs and requirements and thus bring higher value to the firms themselves (Gnday G. at al, 2010). In other words, they are related to the realization of results of commercial significance. They are the key to achieving competitiveness. However, not all enterprises succeed in their innovation activity, although they operate under the same or similar conditions of the external environment. The reason for this is that they have a different ability to recognize, adopt, develop and use innovations in a timely manner, i.e. they have different innovation capacity. It is precisely its level and the level of its forming factors that are at the basis of the innovation activity of enterprises and the achievement of long-term economic success.

The innovation capacity of enterprises is the result of planned managerial efforts to shape and develop the internal conditions for adopting and using new knowledge. Therefore, it is very important to determine where to put in the efforts so that the best result is achieved. This is the important question to be answered by determining the relative importance of each of the internal factors.

\footnotetext{
1 Technical University of Sofia

2 Technical University of Sofia
} 


\section{Articles}

According to Neely A. and Hii J. from the University of Cambridge (Neely A., Hii J., 2012) the innovation capacity is the potential of the firm to generate innovation results. Similar, but more detailed, is the definition that innovation capacity is the ability of the firm to identify the trends and the new technologies but also to acquire and exploit this knowledge and information (Bessant and Pavitt, 2005).

The innovation capacity of the company is closely related to and often identified with another important concept - absorption capacity, i.e. the ability of the company to learn and take advantage of the knowledge that has emerged and spread in society. Cohen and Levinthal determine the absorption capacity in the following way: it is "the ability of the company to recognize the value of the new, external information for it, to absorb it and to use it to achieve commercial results" (Cohen, W., and Levinthal, D., 1990 and 1994). In turn, Zahra and George (Zahra, S. and George, G., 2002) develop this concept and define it as the ability of the company to acquire, assimilate, transform and exploit new knowledge and technologies from the external environment. Further clarification of the similarity of the two categories discussed is given by $P$. Lane, $B$. Koka and $S$. Pathak (Lane P., Koka, B. and Pathak, S., 2006) who define absorption capacity as the company's ability to exploit environmental knowledge through three successive processes: (1) recognition and understanding of potentially important new knowledge outside the company through learning, (2) adopting significant new knowledge through transformation and (3) using the existing knowledge to create new knowledge and commercial results by exploiting them.

The identification of the two categories discussed is to a considerable extent valid for Bulgarian enterprises given the fact that most of them are small and medium in size and do not have their own facilities and opportunities for self-development. They rely on external ideas and developments (Idriz F., 2018).

The more topical the issues and the importance of innovations get, the higher the interest in theoretical clarification and empirical study of various aspects of the innovation capacity of enterprises. The number of scientific publications in these areas of research is growing. However, a number of important issues require additional research, which justifies the need to conduct new studies in certain areas. Such an area of research is the study of the impact of the factors of the innovation capacity of enterprises on their innovative activity.

In view of the above, the aim of this paper is to present the findings of an empirical study of the impact of the factors of innovation capacity on the innovative activity of some industrial enterprises in Bulgaria. The authors hope to instigate a discussion on these issues and other similar questions related to the topic, the results of which will aid enterprises in taking managerial decisions on both streamlining innovative efforts and investment, and developing strategies for further growth.

\section{Factors of the innovation capacity of enterprises.}

Specialised literature discusses a great variety of determinants (internal conditions) and factors which determine and influence the innovation capacity of enterprises. Neely A. and Hii J. (Neely A., Hii J., 2012) divided them into four groups: corporate culture, which contributes to the search process and the introduction of novelties; the resources of the firm - financial, labor and material; the firm competences, which determine its ability to explore innovative ideas - in technology, in marketing, etc.; existing knowledge and ideas.

According to Cohen W. and Levinthal D. (Cohen, W., and Levinthal, D., 1990.) 


\section{Articles}

the absorption capacity is formed by the knowledge already accumulated in the enterprise and its staff and is the by-product of its research and innovation activities. They indicate the following main factors: a/ technological capabilities of the environment the quantity of available technological knowledge, potential improvements in technologies; b/ characteristics of external knowledge that determine the ease with which it will be acquired by the firm - similarity with the internal needs, complex development; c/ possibility for free dissemination of knowledge in the industry - as opposed to the degree of protection of intellectual property; $d$ / competitiveness of the firm; e/ demand - increasing demand and revenue elasticity; f/ price elasticity.

Other authors (Hasan, S., Othman, A., Mustafa, Sh., Wahab, W., and Ismail, H., 2011., Tsvetanova, A.) add the following determinants of the innovation capacity: a/ capability of the company employees, i.e. the ability of the staff to discover and acquire new information. It depends on their education, qualifications and experience: $b /$ the ability of the firm to disseminate knowledge among its members of staff; c/ corporate culture oriented at seeking new opportunities; $d /$ capability in the field of research and innovation - the intensity of research and innovation in the enterprise lead to the accumulation of knowledge and experience, generate a search for new technological opportunities and build up its absorption capacity; e/ communication opportunities in the enterprise - they refer to the possibility to share information among the individuals and the departments in the enterprise in order to have common understanding of the assessment of new knowledge and action points.

Specialised literature features models of the absorption capacity of the enterprise, which reflect the dynamic character of the
Study of the Impact of Innovation Capacity Factors on the Activation of Company's Innovation Activity

process evolving under the supervision of the management. Thus, for example, (Volbersa, H., Foss, N. and Lyles, M., 2009) point out the following main determinants: a/ the conditions of the environment - dynamics, competition, characteristics of the knowledge available, mode of its dissemination; b/ amount and structure of the knowledge the firm has; c/ management - managerial knowledge, combinatory ability, development and dissemination of individual knowledge; $d$ / organisation of the firm - form of organisation, system of stimuli used; information network, internal communication; e/ intercompany interaction - generation and dissemination of knowledge, system of managing cooperation, network for the generation and transfer of knowledge, similarity between organisations.

According to Lane P. et al. (Lane, P., Koka, B., 2006), the main factors forming the innovation capacity of the firms are: a/ the conditions of the environment - they stimulate the building up of the absorption capacity; b/ the characteristics of the available internal and external knowledge - they create conditions for broad and in-depth understanding; $c /$ the characteristics of the relationships - they facilitate mutual understanding; $d /$ corporate structure - it ensures focus on the recognition, understanding, acquisition and use of knowledge; e/ the characteristics of the mindset model of the members of staff in the firm - it facilitates recognition, acquisition and use of knowledge; $f$ / characteristics of the corporate structures and processes - they stimulate the efficiency and effectiveness of acquisition and use of knowledge.

In the model developed in (Velev M., Atanasova S., 2013) the determinants and the factors, which determine the innovation capacity of enterprises, are divided into three groups (Fig.1):

- Determinants of the capacity. These are factors internal for the enterprise, 


\section{Articles}

which create potential for absorbing new technologies and for innovation. The higher level of their development facilitates the prompt acquisition of novelties in the enterprise and vice versa. The level of development of these factors is to a great extent the result of the development of the enterprise itself. It is a consequence of the efforts managers have made.

- Factors, internal for the enterprise, which influence the determinants of the capacity.
- Factors of the environment. They impact mainly the corporate determinants of the absorption/innovation capacity and thus to a great extent create conditions for its enhancement or reduction. Some of these are elements of the business environment and directly affect the determinants, while others are elements of the macro environment (economic conditions, legal conditions, demographic conditions, scientific and technical progress, etc.) and directly impact the determinants and the factors of the business environment.

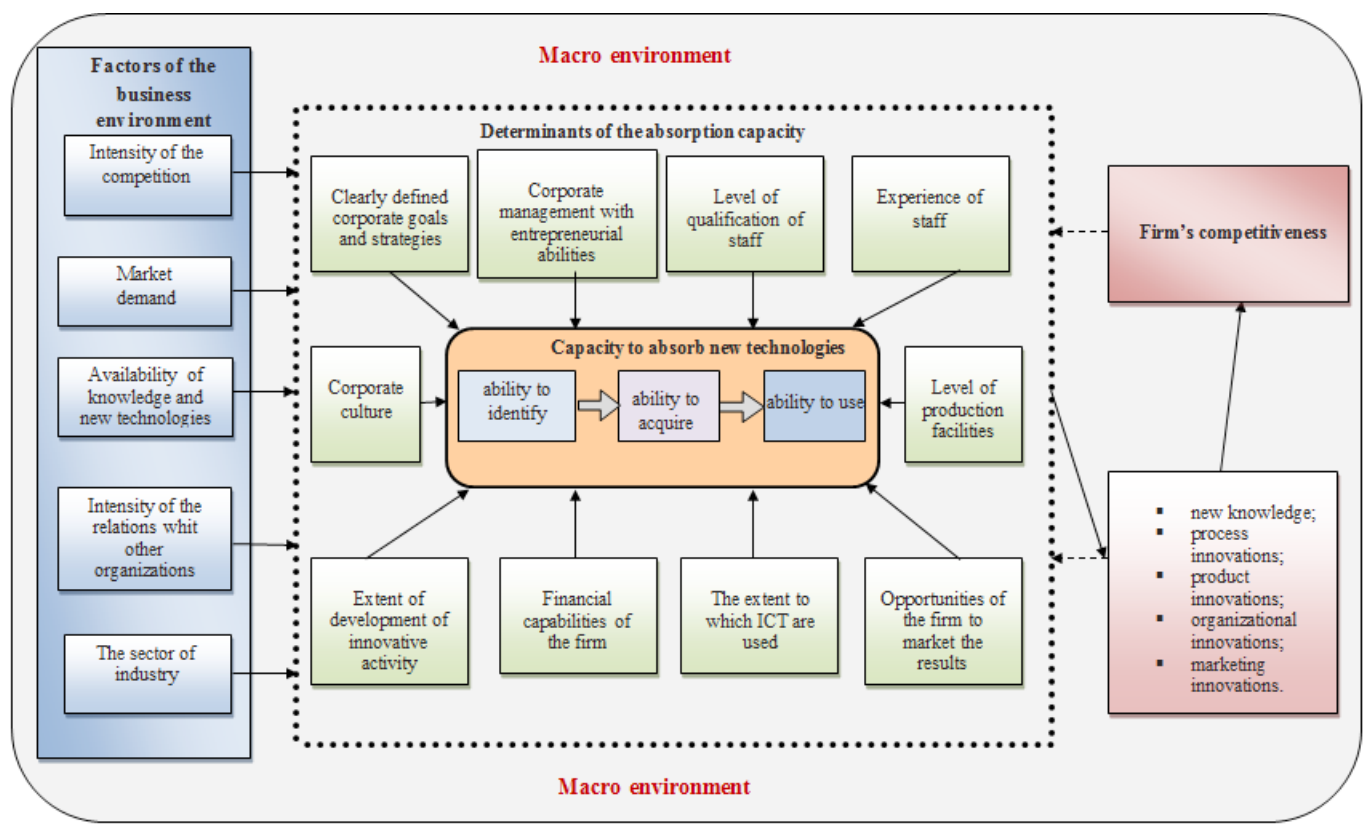

Fig 1. Factors of the absorption/innovation capacity of the enterprises

The system of determinants and factors presented above will be used for the purposes of this paper (Velev M., Atanasova S., 2013)

\section{Methodology}

The aim of the empirical study was to $1 /$ determine the managers' assessment of the importance of the factors of innovation capacity for activation of company innovation activity; 2/ determine the state of the determinants of innovation capacity of studied enterprises; $3 /$ assess the impact of the determinants on the innovative activity and the business results of enterprises. The findings of this research would facilitate management in decisionmaking with regard to directing innovation efforts and investment as well as the drafting of strategies for further development.

The approach adopted in the research is based on the collection, processing and analysis of considerable amount of empirical information from industrial enterprises in 


\section{Articles}

Bulgaria by means of a specially developed methodology of research and statistical methods and specialized software for processing and analyzing the information.

The study was conducted with Bulgarian enterprises and lasted over a period of two years (2016 - 2017). It was carried out using the survey method, the respondents being company managers. A specially prepared questionnaire was used and it was sent by post and e-mail to a large number of industrial enterprises. Unfortunately, because of the low percentage of completed questionnaires the chosen method had to be complemented with interviews conducted at the workplace. The respondents shared their opinion on each of the questions using a grading system. The grade for each indicator is within the range from 1 to 7 . The lowest grade of 1 shows a very low level or importance, and the highest one of 7 - excellent state or maximum significance. The IBM SPSS Statistics 19 software product was used to process the results of the study.

The preliminary study of the literature gave us grounds to formulate the following research hypothesis: there is a positive correlation between the level of the determinants and factors of the innovation capacity of enterprises and their innovative activity.

In order to prove the positive effect of the level of the determinants of the innovation capacity on the technological transfer, innovation and business results, the enterprises in the survey were divided into two groups according to the level of development of their determinants: Group 1 - enterprises with a level below the average one for the survey and Group 2 - enterprises with a level above the average one. The aim was to compare them in terms of technological transfer, innovation activity and the achieved business results and on that basis carry out
Study of the Impact of Innovation Capacity Factors on the Activation of Company's Innovation Activity

a logical analysis and interpretation of the results.

The main stages of the evaluations and analyses performed in the publication are:

Step 1. Assessing the average level of the determinants of the innovation capacity of the sampled enterprises.

Step 2. Dividing the enterprises into groups according to the level of development of their determinants;

Stage 3. Determining the number of innovations carried out by groups of enterprises. Comparative analysis.

Step 4. Assessing the importance of determinants and business environment factors for activating the innovation activity of enterprises.

Stage 5. Assessing the positive results of the enterprises by groups depending on the level of development of their determinants and by years. Comparative analysis.

The level of determinants of the innovation capacity of the entire population of surveyed enterprises was defined by years as the arithmetic mean-weighted values of their level estimates, using the number of enterprises with the corresponding level by weight, ie:

$$
\mathrm{Rd}=\frac{\sum_{\mathrm{i}=1}^{7} \text { Pdi.Qdi }}{\sum_{\mathrm{i}=1}^{7} \mathrm{Qdi}}
$$

Where:

$\mathrm{Rd}$ is the average level of the $\mathrm{d}$-determinant of the innovation capacity of the entire population of surveyed enterprises (1 to 7);

$\mathrm{Pdi}$ is the $\mathrm{i}$-th level of the $\mathrm{d}$-determinant (from 1 to 7);

Qdi is the number of enterprises in the survey population with the i-th level of the d-determinant;

In the same way, the importance of the internal factors of the determinants and the factors of the business environment for activating the innovation activity of the enterprises was determined. The positive results achieved for enterprises as a result 


\section{Articles}

of innovations were defined as the arithmetic weighted average of the estimates for improving the relevant indicators, using the number of enterprises with such estimates by weight. They are determined by year and by group, depending on the level of development of their determinants.

\section{Findings}

The findings presented here are for 100 industrial enterprises from the whole country. The studied enterprises are not representative of the Bulgarian economy, but the results are interesting and indicative of the state of the factors affecting the innovation capacity and their impact on the corporate results. They can be discussed and used as a basis for directing the efforts of the enterprises to improve their competitiveness.

The limited size of the present paper does not make it possible to present the results of the conducted study. That is why here we present only the summarized results for all the studied enterprises.

Out of all the industrial enterprises in the study $60 \%$ are located in Sofia, $20 \%$ - in big cities and $20 \%$ in small settlements. The share of small and medium-sized enterprises in the study is $80 \%$. It was found out that in $201640 \%$ of the studied enterprises implemented innovation and in 2017 - 52\% (Table 1.). This percentage is higher than the data about innovative enterprises in the industry given in the official statistics for the country (Statistical yearbook 2017). This is mainly due to the lack of representativeness of the present research. It was found out that most innovations introduced by enterprises resulted from technological transfer, i.e. they were introduced on the basis of acquired external knowledge, methods and processes, documentation, patents, software products, design, physical objects. Over the research period technological transfer was made by
$39 \%$ of the studied enterprises in 2016 and 51 $\%$ in 2017. Only a small part of the innovations are introduced through their own means and they are at a low level of novelty and importance of change.

Table 1. Number of implemented innovations in the studied enterprises

\begin{tabular}{|l|l|l|l|}
\hline \multirow{2}{*}{ № } & \multirow{2}{*}{ Type of the innovation } & \multicolumn{2}{|l|}{$\begin{array}{l}\text { Implemented } \\
\text { innovation } \\
\text { in the enterprises }\end{array}$} \\
\cline { 3 - 4 } & & $\mathbf{2 0 1 6}$ & $\mathbf{2 0 1 7}$ \\
\hline 1. & Process innovations & 9 & 13 \\
\hline 2. & Product innovations & 13 & 17 \\
\hline 3. & Organizational innovations & 7 & 7 \\
\hline 4. & Marketing innovations & 7 & 11 \\
\hline \multirow{2}{*}{ 5. } & $\begin{array}{l}\text { Complex innovations } \\
\text { (several types of }\end{array}$ & 6 & 8 \\
\hline innovations) & Overall & $\mathbf{4 2}$ & $\mathbf{5 6}$ \\
\hline
\end{tabular}

According to the managers interviewed in the survey, the innovations introduced by their enterprises were not at a high level of novelty and significance of change. What should be noted is that during the research period the number and the level of the marketing innovations grew. A drop in the level of product innovations was observed. The grades for level of innovation demonstrated that in the enterprises there were usually small, insignificant changes with a low level of novelty, which involve lower costs and lead to lower effectiveness. It is logical to expect that this had an effect on the economic results.

We can assume that the comparatively low level of innovation and technological transfer, assessed in terms of the degree of novelty and significance of the change is due to the not very high level of the innovation capacity and the determinants forming it. The study confirmed that assumption. The grades given by the managers, who participated in the survey, when summarized for the whole study, and defined within the range from 1 


\section{Articles}

(very low level) to 7 (the highest level), are shown in the following table:

Table 2. The level of the determinants of the innovation capacity for the studied enterprises

\begin{tabular}{|c|c|c|}
\hline \multirow{2}{*}{ Determinants } & \multicolumn{2}{|c|}{$\begin{array}{l}\text { The level of the } \\
\text { determinants }\end{array}$} \\
\hline & 2016 & 2017 \\
\hline $\begin{array}{l}\text { Clearly defined corporate } \\
\text { goals and innovative } \\
\text { strategies }\end{array}$ & 3.0 & 3.1 \\
\hline $\begin{array}{l}\text { Availability of entrepreneurial } \\
\text { corporate management }\end{array}$ & 4.2 & 4.3 \\
\hline Staff with high education & 3.6 & 3.7 \\
\hline $\begin{array}{l}\text { Staff with technical education } \\
\text { (secondary and tertiary) }\end{array}$ & 4.2 & 4.0 \\
\hline Staff experience & 4.1 & 4.2 \\
\hline $\begin{array}{l}\text { Corporate culture facilitating } \\
\text { the search for and the } \\
\text { introduction of novel ideas } \\
\text { and developments }\end{array}$ & 3.1 & 3.1 \\
\hline Level of production facilities & 3.8 & 4.4 \\
\hline $\begin{array}{l}\text { Extent of development of } \\
\text { innovative activity }\end{array}$ & 3.7 & 3.8 \\
\hline $\begin{array}{l}\text { Financial capabilities of the } \\
\text { enterprise }\end{array}$ & 3.0 & 3.3 \\
\hline $\begin{array}{l}\text { The extent to which } \\
\text { information and } \\
\text { communications technologies } \\
\text { are used }\end{array}$ & 5.3 & 5.9 \\
\hline $\begin{array}{l}\text { Opportunities of the } \\
\text { enterprise to market the } \\
\text { results of the introduced new } \\
\text { technologies }\end{array}$ & 2.9 & 3.2 \\
\hline
\end{tabular}

The average level of all determinants of the innovation capacity for all the studied enterprises is 3.71 for 2016 and 3.91 for 2017. For the two years it is slightly over the middle of the assessment scale and is certainly not enough to conduct intensive and qualitative innovation activity. The major part of the determinants is not well developed in the enterprises and the efforts of the managers need to be focused on their improvement. Still there was some improvement in 2017.
Study of the Impact of Innovation Capacity Factors on the Activation of Company's Innovation Activity

For the purposes of the present research the enterprises in the survey were divided into two groups according to the level of development of their determinants of the innovation capacity: Group 1 - enterprises with a level under the average one for the study, Group 2 - enterprises with a level over the average one. The aim was to compare them in terms of innovation activity and accomplished business results.

In the managers' opinion the determinants of the innovation capacity are of the greatest importance for implementing successful product and process innovations in enterprises. It should be pointed out that the grades of the importance of the determinants given by managers of enterprises, which did not have a technological transfer during the research period, do not differ significantly from those of the managers of the other enterprises.

It was established that the main part of innovations in the enterprises were the result of a horizontal transfer of technologies, i.e. transfer of technologies from one organization to another within the same stage of their life cycle. A small part of the technological transfers were vertical, i.e. they were transfers of new technologies in different stages of their life cycle from research organisations to the place (organisation) of their adoption. This is indicative of the bad cooperation in the field of innovation between enterprises and universities and scientificresearch organisations. In 2016 only 3 of the transfers were vertical, and all of them were in enterprises from Group 2. In 2017 there were only 7 and only one of them was in an enterprise from Group 1.

According to the managers who participated in the study, the innovations made by their enterprises were of relatively low level in terms of degree of novelty and significance of the change. For 2016 their average level is graded as 3.46 for Group 1 


\section{Articles}

and 3.65 for Group 2, and for 2017- 3.46 and 4.10 , respectively. There is a slight trend for a step-by-step transition from the introduction of insignificant innovations to having larger ones but the lagging behind of the enterprises in Group 1 is obvious. There is also a difference in the number of implemented innovations, which can be seen in the following table:

Table 3. Number of implemented innovations by group of enterprises according to the level of the determinants of the innovation capacity

\begin{tabular}{|c|c|c|c|c|c|}
\hline \multirow{3}{*}{ № } & \multirow{3}{*}{ Type of innovation } & \multicolumn{4}{|c|}{ Innovations made by the group of enterprises } \\
\hline & & \multicolumn{2}{|l|}{2016} & \multicolumn{2}{|l|}{2017} \\
\hline & & Group 1 & Group 2 & Group 1 & Group 2 \\
\hline 1. & Process innovations & 3 & 6 & 4 & 9 \\
\hline 2. & Product innovations & 5 & 8 & 6 & 11 \\
\hline 3. & Organisational innovations & 3 & 4 & 2 & 5 \\
\hline 4. & Marketing innovations & 2 & 5 & 3 & 8 \\
\hline 5. & $\begin{array}{l}\text { Complex innovations (several types of } \\
\text { innovations) }\end{array}$ & 1 & 5 & 2 & 6 \\
\hline \multicolumn{2}{|c|}{ Overall } & 14 & 28 & 17 & 39 \\
\hline
\end{tabular}

The specified determinants, which create the potential of the enterprise to innovate, are affected by some internal company factors, which also need to be considered and where the efforts of the mangers need to be concentrated so that they get improved. The study demonstrated that managers appreciate the importance of these factors. The averaged results obtained are:

Table 4. Importance of the internal corporate factors forming the determinants for the innovation activities of enterprises

\begin{tabular}{|l|l|}
\hline $\begin{array}{l}\text { Factors in forming the } \\
\text { determinants }\end{array}$ & $\begin{array}{l}\text { Overall } \\
\text { importance for } \\
\text { the innovation } \\
\text { activity }\end{array}$ \\
\hline 1. The size of the firm & 5.27 \\
\hline $\begin{array}{l}\text { 2. The degree of diversification } \\
\text { of the activities of the } \\
\text { enterprise }\end{array}$ & 5.20 \\
\hline $\begin{array}{l}\text { 3.Combination of various types } \\
\text { of innovation }\end{array}$ & 5.14 \\
\hline 4. Ownership of the enterprise & 4.72 \\
\hline 5. Planning horizon & 5.11 \\
\hline Overall importance & 5.09 \\
\hline
\end{tabular}

Managers consider the size of the enterprise to be the most significant factor in forming the determinants of its innovation capacity and in activating the innovation activity. Apparently, they relate it to better provision of big enterprises with resources and their capability to further the qualifications of staff needed for its development and innovations. This is the opinion mainly of respondents from small and medium-sized enterprises, which constitute $80 \%$ of the study. According to them, the shortage of resources makes research activity and innovations more difficult. It is obvious that diversification of activities is also of great importance for the development of the innovation capacity. It makes the activities of enterprises more complex and compels management to seek ways to improve their state.

The managers, who participated in the survey, point out the different positive influence of the factors of the business environment on the formation of the corporate determinants of the innovation capacity on the innovation activity of the enterprises. Their average grades are given in Table 5: 


\section{Articles}

Table 5. Importance of the factors of the business environment for activating the innovation activities of enterprises

\begin{tabular}{|l|l|}
\hline $\begin{array}{l}\text { Factors of the business } \\
\text { environment }\end{array}$ & $\begin{array}{l}\text { Overall } \\
\text { importance for } \\
\text { the innovation } \\
\text { activity }\end{array}$ \\
\hline $\begin{array}{l}\text { 1. Availability of knowledge and } \\
\text { new technologies }\end{array}$ & 3.68 \\
\hline $\begin{array}{l}\text { 2. The sector of industry in } \\
\text { which the enterprise operates }\end{array}$ & 4.45 \\
\hline $\begin{array}{l}\text { 3. Intensity of the competition } \\
\text { on the markets where the firm } \\
\text { operate }\end{array}$ & 5.35 \\
\hline $\begin{array}{l}\text { 4. Market on which the } \\
\text { enterprise operates }\end{array}$ & 5.04 \\
\hline $\begin{array}{l}\text { 5. Participation in production } \\
\text { unions and associations }\end{array}$ & 4.30 \\
\hline $\begin{array}{l}\text { 6. Partnership in the field of } \\
\text { technological transfer with other } \\
\text { firms }\end{array}$ & 3.90 \\
\hline $\begin{array}{l}\text { 7. Partnership in the field of } \\
\text { technological transfer with } \\
\text { universities }\end{array}$ & 4.31 \\
\hline 8. Location of the firm. & 3.42 \\
\hline Overall importance & 4.31 \\
\hline
\end{tabular}

According to the managers, the intensity of the competition and the characteristics of demand on different markets has the most positive influence on the innovation activity. They think this is due to the pressure which the competition and the size and quality of
Study of the Impact of Innovation Capacity Factors on the Activation of Company's Innovation Activity

demand put on the firms for faster introduction of new ideas and developments. They give the least importance to the location of the firms and the availability of knowledge and new technologies. This can be explained with the development of communications and the free dissemination of knowledge globally, which facilitate access to them and their transfer. We should note the relatively low importance which is given to partnership with other firms in the field of innovation, which is apparently due to the insufficient development of clusters and various other forms of cooperation among organisations in the country.

The assessment of the impact of the innovation capacity on the business results of the enterprises is based on the understanding that it leads to the introduction of innovations, which in turn improves the overall results of enterprises. In order to determine that impact we compared the grades of the managers from the first and the second group, which evaluated the dynamics of some indicators of their enterprises. The grades for the achieved change, as compared to those from the previous year, are within the range from 1 - no improvement has been made, to 7 - a great improvement has been made. The summarized results are presented in the following table:

Table 6. Positive results for the enterprises

\begin{tabular}{|l|l|l|l|l|l|}
\hline \multirow{2}{*}{ № } & Results & \multicolumn{3}{|l|}{$\begin{array}{l}\text { Enterprises } \\
\text { from group 1 }\end{array}$} & \multicolumn{2}{l}{$\begin{array}{l}\text { Enterprises } \\
\text { from group 2 }\end{array}$} \\
\cline { 3 - 6 } & & $\mathbf{2 0 1 6}$ & $\mathbf{2 0 1 7}$ & $\mathbf{2 0 1 6}$ & $\mathbf{2 0 1 7}$ \\
\hline 1. & Increase of the production capacity & 1.2 & 1.6 & 3.2 & 4.5 \\
\hline 2. & Enhancement of the flexibility of the activities of enterprises & 1.0 & 1.3 & 1.5 & 2.9 \\
\hline 3. & Improved conformity with standards & 3.1 & 3.0 & 3.2 & 3.8 \\
\hline 4. & Improved protection of the environment & 1.3 & 1.5 & 2.7 & 4.0 \\
\hline 5. & Improved quality of management activity & 1.3 & 1.3 & 3.1 & 3.5 \\
\hline 6. & Improved quality of the marketing activity & 2.4 & 3.1 & 4.4 & 5.0 \\
\hline 7. & Improved quality of products/services & 3.2 & 3.6 & 4.5 & 5.6 \\
\hline 8. & Increase in sales & 2.1 & 2.9 & 3.7 & 4.8 \\
\hline
\end{tabular}




\begin{tabular}{|l|l|l|l|l|l|}
\hline № & Results & \multicolumn{2}{|l|}{$\begin{array}{l}\text { Enterprises } \\
\text { from group 1 }\end{array}$} & $\begin{array}{l}\text { Enterprises } \\
\text { from group 2 }\end{array}$ \\
\cline { 3 - 6 } & & $\mathbf{2 0 1 6}$ & $\mathbf{2 0 1 7}$ & $\mathbf{2 0 1 6}$ & $\mathbf{2 0 1 7}$ \\
\hline 9. & Increase in labour productivity & 1.9 & 2.3 & 3.5 & 4.3 \\
\hline 10. & Reduction of costs per unit of production in enterprises & 3.1 & 3.4 & 4.3 & 4.5 \\
\hline 11. & Improved financial results of enterprises & 2.9 & 3.2 & 3.8 & 4.1 \\
\hline 12. & Improved competitiveness of enterprises & 2.3 & 2.5 & 3.6 & 4.5 \\
\hline $\begin{array}{l}\text { The grades are within a range from 1 - no improvement has been made, to 7 - a great improvement has } \\
\text { been made. }\end{array}$ & \\
\hline
\end{tabular}

These results demonstrate a positive correlation between the level of the innovation capacity of enterprises and the business results. It becomes obvious not only from the difference observed between the indicators of the two groups of enterprises, but also from the noticeable trend in their improvement in the second year. The better level of the determinants was conductive to the introduction of successful innovations, which led to the improvement of the business indicators too. However, the improvement of some of these results is also due to the improving economic situation in the country. What is more, the improvements are the result not only of the innovative efforts in the two years but also of such efforts in previous years. The results from previous years were due to the level of the determinants then, but the results have also contributed to the improvement of the state of the determinants.

\section{Conclusion}

The paper presents briefly the findings of an empirical study of the state of the factors of the innovation capacity of industrial enterprises in Bulgaria and their impact on the innovative activity and business results of the enterprises. Due to the limited number of enterprises, which were included in the survey the obtained results are not representative of the Bulgarian industry as a whole but are interesting and indicative of the effect of the improved factors of innovation capacity. They can be the basis of discussion and can serve to direct the efforts of enterprises to improve their competitiveness.

It was found out that the average level of the determinants of the innovation capacity for all the studied enterprises is not high. For the two years it is slightly over the medium level of the grading scale (from 1 to 7 ) and is definitely not enough to have intensive and quality innovation activity.

The study has confirmed the research hypothesis that there is a positive correlation between the level of the determinants and the factors of innovation capacity of the enterprises and their innovative activity.
According to the managers, the importance of the determinants for having quality innovations is relatively high. The group of enterprises with an average level of determinants of the innovation capacity or with a level over the average one for the study have significantly more intensive activity in the field of innovation than the other group.

According to the managers who participated in the study, the innovations introduced by their enterprises were of a relatively low level in terms of the degree of novelty and significance of change. The level of novelty of enterprises with a level of determinants under the average one for the studied enterprises is also lower.

Regarding the improvement of the state of the determinants, it was found out that a number of internal corporate factors have considerable impact on the formation of the determinants of the innovation capacity and on the innovation activity of the enterprises. The managers should put in efforts to improve them. The study has shown the different importance of the factors of the business environment. Taking them into account is important for achieving success. 


\section{Articles}

What was also confirmed was the positive correlation between the level of determinants of the innovation capacity of enterprises and their business results. There was a difference in the indicators of the two groups of enterprises (with a level of determinants over and under the average for the survey), as well as a different tendency for their improvement in the second year of the study. The better level of the determinants was favorable for the introduction of successful innovations, which in turn also led to the improvement of business indicators of enterprises.

As a whole, the research findings demonstrate the great importance of the determinants of the innovation capacity for the competitiveness and business success of enterprises. The study is a good base for channelling managerial efforts in the right direction in order to guarantee the sustainable development of enterprises.

\section{References:}

Cohen, W., and Levinthal, D., 1990, Absorptive Capacity: A new perspective on learning and innovation, Administrative Science Quarterly, Vol. 35;

Cohen, W., and Levinthal, D., 1994, Fortune Favors the Prepared Firm, Management Science;

Gnday G. at al, Effects of Innovation Types on Firm Performance, study of Faculty of Engineering and Natural Sciences, Sabanci University, 2010;

Hasan, S., Othman, A., Mustafa, Sh., Wahab, W., and Ismail, H., 2011, Development of Absorption Capacity
Study of the Impact of Innovation Capacity Factors on the Activation of Company's Innovation Activity

Attributes for Technology Transfer Performance: A Pilot Study in National Automotive Industri, International Management Conference 2011, 16-17.04.2011, University Sultan Zainal Abidin;

Idriz F., 2018, Product innovations in tourism, Softtrejd, Sofia;

Lane P., Koka, B. and Pathak, S., 2006, The Reification of Absorptive Capacity: A Critical Review and Rejuvenation of the Construct, Academy of Management Review, 2006, Volo. 31, No 4;

Neely A., Hii J., The Innovative Capacity of Firms, Nang Yan Business Journal, 1.1.2012; Statistical yearbook 2016, National statistical institute of Republic of Bulgaria, 2016, p.414;

Tsvetanova, A. „Determining the Modules / Activities with Potential for Outsourcing in Realization of the Strategy of Mass Customization" First International Conference „Project Management" - Tryavna, April, 2011; Velev M., Atanasova S., 2013, The technology transfer in Industrial firm, Softrejd, Sofia;

Volbersa, H., Foss, N. and Lyles, M., 2009, Absorbing the Concept of Absorptive Capacity: How To Realize Its Potential in the Organization Field, Center for Strategic Management and Globalization, Copenhagen Business School, Frederiksberg, Denmark.

Zahra, S. A. and G. George (2002). „Absorptive capacity: A review, reconceptualization, and extension."Academy of Management Review 27(2): 185-203. 